Article

\title{
Landslide-Induced Damage Probability Estimation Coupling InSAR and Field Survey Data by Fragility Curves
}

\author{
Matteo Del Soldato ${ }^{1} * \mathbb{C}^{\mathbb{D}}$, Lorenzo Solari ${ }^{1}{ }^{1}$, Francesco Poggi ${ }^{1}$, Federico Raspini ${ }^{1}$, \\ Roberto Tomás $^{2}$ (D) Riccardo Fanti $^{1}$ and Nicola Casagli ${ }^{1}$ (D) \\ 1 Earth Sciences Department, University of Firenze, Via La Pira 4, 50121 Firenze, Italy; \\ lorenzo.solari@unifi.it (L.S.); francesco.poggi7@stud.unifi.it (F.P.); federico.raspini@unifi.it (F.R.); \\ riccardo.fanti@unifi.it (R.F.); nicola.casagli@unifi.it (N.C.) \\ 2 Departamento de Ingenieria Civil, Universidad de Alicante, 03690 Alicante, Spain; roberto.tomas@ua.es \\ * Correspondence: matteo.delsoldato@unifi.it; Tel.: +39-055-275-7548
}

Received: 16 May 2019; Accepted: 17 June 2019; Published: 22 June 2019

\begin{abstract}
Landslides are considered to be one of the main natural geohazards causing relevant economic damages and social effects worldwide. Italy is one of the countries worldwide most affected by landslides; in the Region of Tuscany alone, more than 100,000 phenomena are known and mapped. The possibility to recognize, investigate, and monitor these phenomena play a key role to avoid further occurrences and consequences. The number of applications of Advanced Differential Interferometric Synthetic Aperture Radar (A-DInSAR) analysis for landslides monitoring and mapping greatly increased in the last decades thanks to the technological advances and the development of advanced processing algorithms. In this work, landslide-induced damage on structures recognized and classified by field survey and velocity of displacement re-projected along the steepest slope were combined in order to extract fragility curves for the hamlets of Patigno and Coloretta, in the Zeri municipality (Tuscany, northern Italy). Images using ERS1/2, ENVISAT, COSMO-SkyMed (CSK) and Sentinel-1 SAR (Synthetic Aperture Radar) were employed to investigate an approximate 25 years of deformation affecting both hamlets. Three field surveys were conducted for recognizing, identifying, and classifying the landslide-induced damage on structures and infrastructures. At the end, the damage probability maps were designed by means of the use of the fragility curves between Sentinel-1 velocities and recorded levels of damage. The results were conceived to be useful for the local authorities and civil protection authorities to improve the land managing and, more generally, for planning mitigation strategies.
\end{abstract}

Keywords: A-DInSAR; landslide; fragility curves; SAR data; Sentinel-1; damage; Tuscany

\section{Introduction}

Landslides are considered to be one of the main natural geohazards causing relevant economic damages and indirect social effects worldwide. Italy is one of the European regions most greatly affected by slope instabilities, with more than 500,000 phenomena already mapped (covering approximatively $7.3 \%$ of its territory) [1]. Landslides can be triggered by natural (e.g., intense rainfalls) or anthropogenic (e.g., deforestation or poor urban planning) factors [2-6]. In both cases, they can impact structures and infrastructures causing considerable socio-economic damages, direct (e.g., maintenance or reconstruction of damaged structures) and indirect (e.g., difficulties to evaluate, losses of services) [1,7-12], as well as fatalities. Spatial and kinematic characterization of landslides, as well as the recognition and classification of landslide-induced damage effects on structures and 
infrastructures [13-16], are fundamental elements to better delineate mass-movement boundaries and for improving land managing.

In recent years, landslide monitoring systems shifted from traditional on site instruments (e.g., conventional wire extensometers [17], inclinometers [18], GPS [19], levelling [20,21]) to remote sensing applications, including Light Detection and Ranging (LiDAR) [22,23], Advanced Differential Interferometry Synthetic Aperture Radar (A-DInSAR), Persistent Scatterers Interferometry (PSI) [24-30] and Small-BAseline Subset (SBAS) [31,32], Ground Based InSAR (GB-InSAR) [33], satellite and aerial imagery investigation [34-36], or Unnamed Aerial Vehicle (UAV) surveys e.g., [37-39]. Unlike ground-based monitoring systems, Earth-observation techniques allow measuring land motion of wide areas with millimetre to centimetre accuracy with a much higher frequency of acquisition and decreasing costs (with respect to reach similar precision with conventional techniques) [40].

Since the late 1990s, the development of A-DInSAR approaches and the evolution of SAR (Synthetic Aperture Radar) sensors have permitted the detection and monitoring of ground deformations with millimetre/centimetre precision over wide areas [41,42]. The A-DInSAR approach has been adopted for local and regional applications for the investigation and monitoring of several types of landslides [26,27,43].

The scientific communities are quite interested in the identification of the most suitable risk areas, as well as mitigation strategies in order to forecast and prevent the possible consequences of activation and reactivation of phenomena. To achieve this objective, a deep knowledge of features of landslides and exposed structures is necessary [44], even if the collection of this information is difficult and several approximations need to be adopted with consequent uncertainties. The availability of SAR archives allows investigating approximatively 25 years of evolution of landslide phenomena. At the moment, the temporal baseline between two consequent images decreased to 6 days, thanks to the Sentinel- 1 constellation, granting a high spatial resolution as well $[45,46]$.

The urban expansion and the population growth are two relevant factors that conduct the people to build in geological or geomorphological critical areas [47]. In many cases, populations have lost the memory of past ruinous landslide events and the disregard of the laws countervailed with several successive amnesties because of infringement have led to continue building in hazardous areas. As a result, the hillslope morphology, caused by terrain remobilization, results modified with consequences on slope instabilities [48]. For these reasons, the monitoring of structures and infrastructures play a key role in the investigation and understanding of slope instabilities on recent constructions. For the urban areas affected by landslides, it is important create a standard procedure for recognizing and classifying different damage levels, in order to help land management authorities [49] to focus and carry out mitigation strategies.

The combination of landslide-induced damage on structure and infrastructure with the ground displacement allows definining the fragility curves of several structures, applying a methodology commonly applied on different engineering fields [50-56]. These curves represent the probability of exceeding a given damage level in a building or infrastructure as a function of ground displacements.

In this work, landslide-induced damage on structures recognized and classified by field survey and velocity of displacement, re-projected along the steepest slope, of single structures assessed by satellite SAR data, were combined in order to build the fragility curves of the hamlets of Patigno and Coloretta in the Zeri municipality (Tuscany, northern Italy).

ERS1/2, ENVISAT, Cosmo-SkyMed (CSK) and Sentinel-1 SAR images were used to investigate about 25 years-long deformation affecting both hamlets. In both sites, some structures and infrastructures suffered serious damage, compromising the stability of some buildings and the functionality of the local road network. A large part of the structures was directly investigated and classified according to the severity of the damage. Then, coupling in situ evidences with A-DInSAR measurements the relative fragility curves were empirically designed for the two investigated hamlets. Finally, since fragility curves represent the probability of structural damage due to ground displacements, once the curves were calibrated for a certain area and period, they were used for the assessment 
of damage probability maps for forecasting consequences on buildings in case of further events or long-term continuous sliding.

The results are conceived to be useful for the local authorities and civil protection authorities to define priorities of intervention, to decide whether or not allocate money for restoring interventions, or, more generally, for planning mitigation strategies.

\section{Study Area}

The area of interest is located in the northern part of the Region of Tuscany (central Italy), named Lunigiana. The two investigated hamlets, Coloretta and Patigno, are localized in the municipality of Zeri (Massa Carrara province) at an elevation ranging between 674 and $708 \mathrm{~m}$ a.s.l. in the northern portion of the Apennines (Figure 1a).

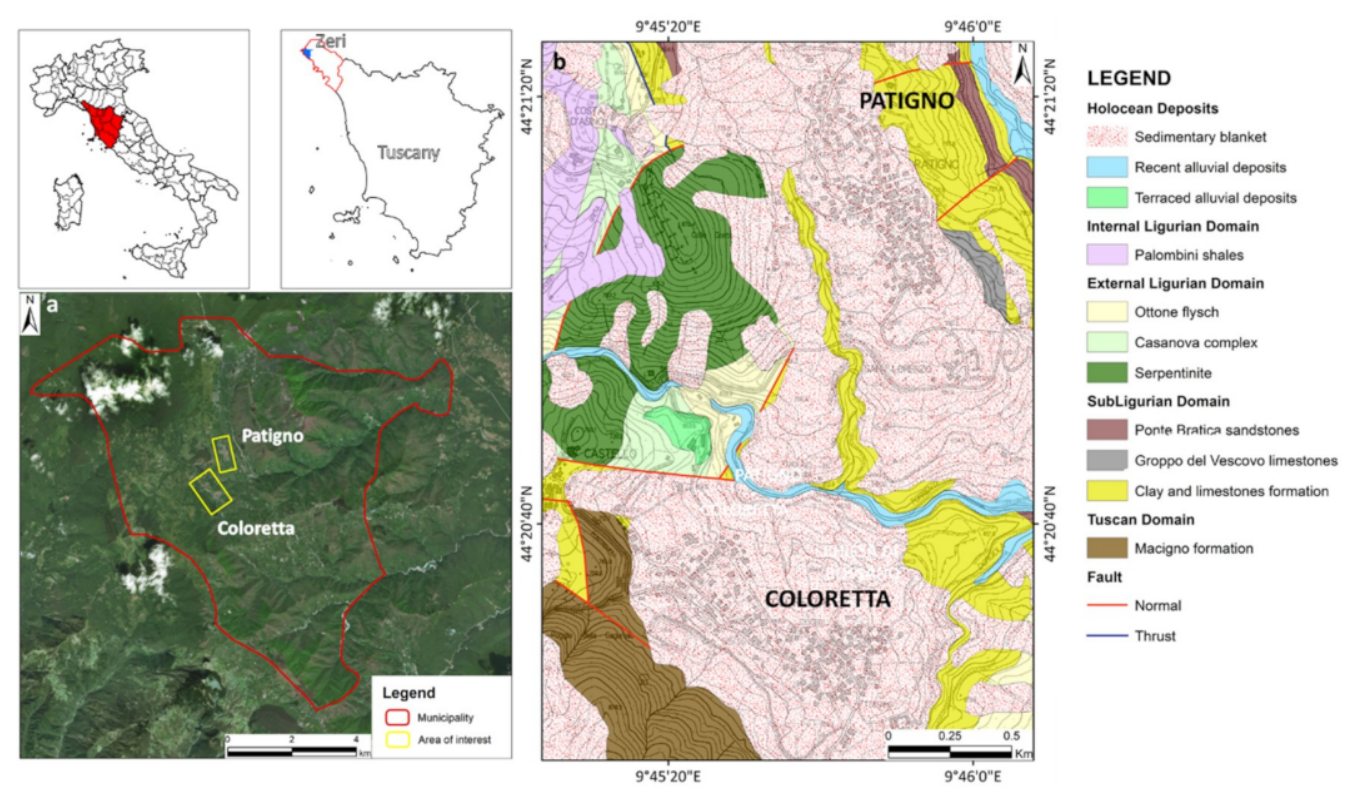

Figure 1. Area of Interest (a) and geology divided in geological domains and formations (b).

According to the classification of Köppen and Geiger [57], the climate of the Zeri municipality is ranked as $\mathrm{Cfb}$, hot and tempered, and is characterized by a tempered and wet summer with a maximum annual temperature lower than $22{ }^{\circ} \mathrm{C}$ and approximatively $18{ }^{\circ} \mathrm{C}$ of maximum annual variation. The area of interest is characterized by relevant precipitation during the whole year, sometimes also during dry months, with an annual average cumulated rainfall of approximatively $914 \mathrm{~mm}$.

From a geological point of view, five different formations and structural domains are typical of the northern sector of the Apennines outcrop in the area of interest (Figure 1b): Holocene deposits, the Internal Ligurian Domain, the External Ligurian Domain, the Subligurian Domain, and the Tuscan Domain $[58,59]$.

Below the Holocene deposits, composed by colluvial and alluvial sediments, the Palombini shales (Internal Ligurian Domain), formed by claystone intercalated with siliceous calcilutite outcrop. In the area, the External Ligurian Domain is represented by the Casanova Complex, heterogeneous units mainly shale with several included olistoliths (e.g., serpentinites, Palombini shale), Ottone flysch with helminthoids and serpentinite. At the bottom of the sequence, the Tuscan domain is mainly constituted by the Macigno Formation, sandstone and flysch, tectonically overlapped by the Subligurian domain here represented by the Ponte Bratica sandstone, Groppo del Vescovo limestone and eluvial deposits, clay and limestone formation. 
The municipality of Zeri is affected by widespread slope instabilities from at least the Pleistocene/Holocene [60], with a continuous alternation of dormant and active periods. In 1957, the instability triggered evident ground effects due to a first phase of the reactivation of the entire landslide in the lower part of the slope of Patigno, mainly defined in 1961 [60]. The main consequences of the slope instabilities can be recognized in the Patigno and Coloretta hamlets where some landslides are nowadays still active.

Patigno is affected by several active and dormant shallow landslides, both connected to a large complex active landslide that involves the urban area and the surrounding woods (Figure 2a). This movement, facing southwest, is approximatively $1.5 \mathrm{~km}$ long and $0.4 \mathrm{~km}$ width in the toe area. This landslide registered various periods of acceleration: 1970, 1972, 1975-1975, 1982-1983, and 1993 [61], leading to severe structures and infrastructures damage. By the comparison of aerophotogrammetry and topographical surveys, the surficial displacement evolution between the 1970s and the 1990s was investigated by Baldi et al. [62] and Raiti et al. [63]. These authors related the landslide activity to heavy rainfall periods that increased pore-water pressure related to the rise of the groundwater table.


Figure 2. Landslide inventory of the Patigno (a) and Coloretta (b) hamlets.

Coloretta is affected as well by several active and dormant landslides, which mainly developed along SW to NE direction (Figure 2b). Again, the long-term activity of the landslide caused important consequences on structures, infrastructure and linear elements. Unfortunately, no historical information about accelerations or reactivations of the landslides affecting this hamlet were found in literature.

\section{Satellite Velocity Maps}

The analysis of the satellite data allows back-analyzing and monitoring the ground deformations that occurred on the areas of interest. Data from ERS1/2, ENVISAT, COSMO-SkyMed, and Sentinel-1 SAR (Synthetic Aperture Radar) were exploited to investigate the evolution of ground motion in the two hamlets from 1993 to 2018. Data from ERS1/2, ENVISAT, and COSMO-SkyMed allowed investigating the behavior of the ground deformation in these areas from 1993 to 2014, and they are 
available over the whole Italian territory thanks to the Portale Cartografico Nazionale (PCN) of the Italian Ministry for the Environment, Territory and Sea (METS) [64].

Sensors for ERS1/2, ENVISAT, and Sentinel-1 acquire SAR images in C-band with a wavelength of about $5.6 \mathrm{~cm}$, while COSMO-SkyMed data, available only in ascending orbit, are acquired in X-band with a wavelength equal to $3.1 \mathrm{~cm}$ (Table 1). ERS1/2 data are available in both ascending and descending orbits and are referred to the period 1992-2000 with a revisiting time of 35 days. ENVISAT data cover the time span between 2003 and 2010 in both ascending and descending geometries with a revisiting time of 24 days. COSMO-SkyMed data cover the period 2011-2014, filling the gap between ENVISAT and Sentinel-1. Sentinel-1 data were acquired in both ascending and descending orbits from March 2015 to June 2018, with a revisiting time of 12 days, up to 6 days considering both Sentinel-1A and 1B. These data derived from the project "Monitoring ground deformation in the Tuscany Region with satellite radar data", founded and supported by the Regional Government of Tuscany and they can be directly downloaded from a dedicate Interferometric SAR satellite website of the Region of Tuscany [65].

Table 1. Available SAR data for the RoI.

\begin{tabular}{ccccccc}
\hline Satellite & $\begin{array}{c}\text { Band } \\
\text { (Wavelength) }\end{array}$ & Orbit & $\mathbf{n}^{\circ}$ Images & Monitored Period & $\begin{array}{c}\text { LOS Angle } \\
\boldsymbol{\theta}\left({ }^{\circ}\right)\end{array}$ & $\begin{array}{c}\text { Azimuth } \\
\text { Angle } \delta\left({ }^{\circ}\right)\end{array}$ \\
\hline ERS1/2 & $\mathrm{C}(5.6 \mathrm{~cm})$ & Ascending & 26 & $\begin{array}{c}\text { 9 July 1992 } \\
\text { 20 August 2000 }\end{array}$ & $\sim 23.0$ & 348.5 \\
\hline ERS1/2 & $\mathrm{C}(5.6 \mathrm{~cm})$ & Descending & 72 & $\begin{array}{c}\text { 6 July 1992 } \\
\text { 30 November 2000 }\end{array}$ & $\sim 23.0$ & 191.5 \\
\hline ENVISAT & $\mathrm{C}(5.6 \mathrm{~cm})$ & Ascending & 35 & $\begin{array}{c}\text { 9 December 2003 } \\
\text { 20 July 2010 }\end{array}$ & $\sim 23.0$ & 345.0 \\
\hline ENVISAT & $\mathrm{C}(5.6 \mathrm{~cm})$ & Descending & 44 & $\begin{array}{c}\text { 8 April 2003 } \\
\text { 15 June 2010 }\end{array}$ & $\sim 23.0$ & 394.0 \\
\hline COSMO-SkyMed & $\mathrm{X}(3.1 \mathrm{~cm})$ & Ascending & 34 & $\begin{array}{c}\text { 7 June 2011 } \\
\text { 28 March 2014 }\end{array}$ & 26.6 & 348.0 \\
\hline Sentinel-1 & $\mathrm{C}(5.6 \mathrm{~cm})$ & Ascending & 128 & $\begin{array}{c}\text { 23 March 2015 } \\
\text { 23 June 2018 }\end{array}$ & 39.8 & 349.3 \\
\hline Sentinel-1 & $\mathrm{C}(5.6 \mathrm{~cm})$ & Descending & 134 & $\begin{array}{c}\text { 22 March 2015 } \\
\text { 22 June 2018 }\end{array}$ & 37.2 & 189.4 \\
\hline
\end{tabular}

The SAR data deriving from the PCN, thus ERS1/2, ENVISAT, and COSMO-SkyMed data were processed according to the Persistent Scatterers Interferometric SAR (PSInSAR) $[66,67]$ and Persistent Scatterers Pairs - Differential Interferometric SAR (PSP-DIFSAR) $[68,69]$ approaches, developed by the companies TRE-Altamira and e-GEOS, respectively.

Sentinel-1 data, however, were processed by means of the SqueeSAR technique [70], an improvement of the PSInSAR algorithm. This approach allows also having information in vegetated areas. In fact, the SqueeSAR approach gives Persistent Scatterers (PS) and Distributed Scatterers (DS), taking advantage of the signal backscattered by reflecting elements (PS), but also by areas that have a low coherent signal along time (DS), such as on grasslands and debris covers.

The products, generally called PS indifferently if they are punctual or areal, give information about the average annual velocity expressed in $\mathrm{mm} /$ year and the displacement occurred at each point along time acquisition by acquisition, expressed in $\mathrm{mm}$. Both measurements are collected along the Line Of Sight (LOS) of the sensor: we are capable to measure only the projection along the LOS of the real movement.

As in the nature of PSI, the urbanized portion of the hamlet are covered by PS, showing a good density of information, while the vegetated areas show no or very few PS products (Figure 3). 



Figure 3. ERS1/2, ENVISAT, COSMO-SkyMed and Sentinel-1 PS data for the Patigno and Coloretta hamlets. Vlos is the velocity measured along the satellite Line of Sight.

\section{Methodology}

For investigating the landslide evolution and the landslide-induced damage affecting Coloretta and Patigno, different approaches were used in addition to A-DInSAR for processing SAR data for the satellite velocity maps: the reprojection of the LOS velocity along the steepest slope, the classification 
of landslide-induced damage, and a statistical approach to combine velocity of displacement and induced effects.

Figure 4 presents the block-diagram of the methodology.

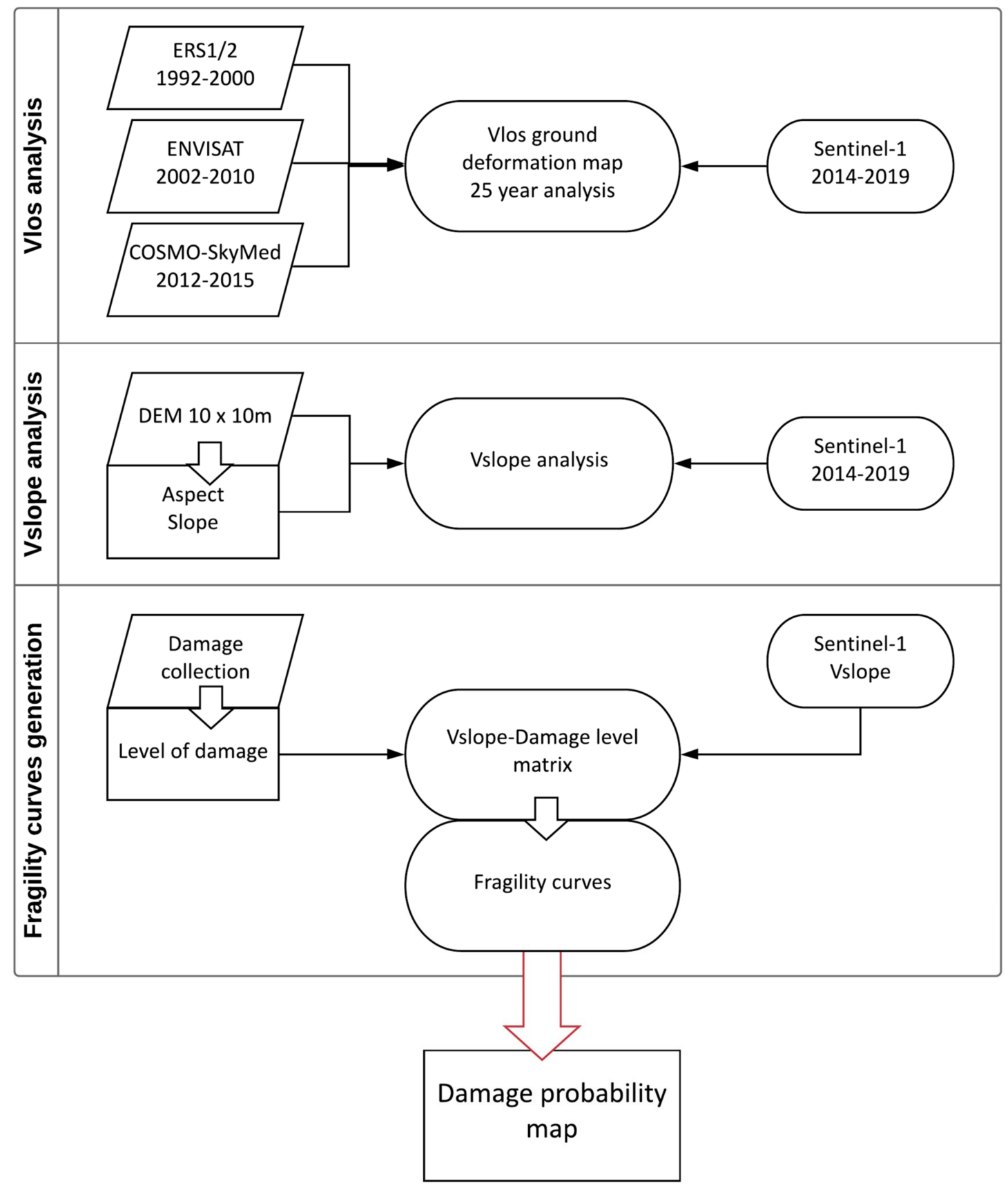

Figure 4. Block diagram of the methodology. Vlos, velocity along the satellite Line of Sight; Vslope, velocity projected along the maximum slope.

\subsection{Velocity Along the Slope}

To investigate the real component of the movement of the monitored landslides affecting the Patigno and Coloretta hamlets, LOS velocity (Vlos) can be transformed into velocity along the slope (Vslope). This conversion is made according to the $\mathrm{C}$ factor based on the satellite and morphological parameters [71] Equation (1).

$$
\text { Vslope }=\frac{\text { Vlos }}{C}
$$


Specifically, the C Equation (2) factor is based on: (i) the cosine directors of the sensors (Nlos, Elos, and Hlos) that depends on the acquisition geometry and on geomorphological parameters of ground surface; (ii) the Aspect (A) that measures the exposure of the slope with respect to the North; and (iii) the Slope (S), that is the steepest angle of descent of the ground surface with respect to the horizontal line. These parameters require a Digital Elevation Model (DEM) for their calculation. For the AoI of the Patigno and Coloretta hamlets, the DEM was downloaded from the website of the Tuscany Region [72].

$$
C=\left(\cos (S) * \sin \left(A-\frac{\pi}{2}\right) *(\text { Nlos })\right)+\left(\left((-1) * \cos (S) * \cos \left(A-\frac{\pi}{2}\right) *(\text { Elos })\right)+((\text { Hlos } * \sin (S)))\right)
$$

where [69]:

$$
\begin{aligned}
& \text { Nlos }=\cos \left(\frac{\pi}{2}-\alpha\right) * \cos \eta \\
& \text { Elos }=\cos \left(\frac{\pi}{2}-\alpha\right) * \cos \omega \\
& \text { Hlos }=\cos (\alpha) \\
& \alpha=\text { incident angle } \\
& \eta=\pi-\theta \\
& \omega=\frac{3}{2} \pi-\theta \\
& \theta=\text { LOS azimuth }
\end{aligned}
$$

To reduce any exaggeration of velocity due to the projection when $C$ tends towards 0 , values between 0 and -0.199 and between 0 and 0.199 were substituted with -0.2 and 0.2 , respectively. Furthermore, the positive values of Vslope velocities were discarded, since velocities climbing up the slope make no sense.

\subsection{Damage Classification}

The approach developed by Del Soldato et. al. [73] was chosen for classifying the landslide-induced damage. This approach does not require to visualize the foundations and the internal portion of the structures and does not consider the site geological context. The methodology revises and improves previous classifications, such as those developed by Chiocchio et al. [48], Alexander [49], Cooper [74], Burland and Wroth [75], and Baggio, et al. [76]. The damage assessment approach proposed by Del Soldato et al. [73] is subdivided into two phases: (1) classification of the landslide-induced damage recognizable on the structures and infrastructure; (2) a posteriori categorization of the entire structure based on the severity of damage classified in Step 1 and on the extension of the damage. In this way, a more precise ranking of damage classes can be estimated for each building. The second phase involves only the damage affecting structures and infrastructure.

The classification considers two types of load-bearing structures: masonry and reinforced concrete frameworks; steel and timber frames are assimilated to reinforced concrete structures, having similar reactions [77]. Masonry is the prevalent building construction typology in both Patigno and Coloretta; just a few reinforced concrete structures are present.

The cracks and fractures on structures and infrastructure as well as on natural and anthropic surfaces can be various and they can be classified into six different classes: (i) no damage: intact building; (ii) negligible: fine and isolate cracks with width lower than $1 \mathrm{~mm}$; (iii) weak: settlement, distortion and inclination of the structure not involving the stability and for cracks with width lower than $5 \mathrm{~mm}$; (iv) moderate: open crack in walls, width up to $15 \mathrm{~mm}$, influencing the strength of the structure; (v) severe: spread cracks and fractures, width up to $25 \mathrm{~mm}$, conditioning the resistance of the structure; and (vi) very severe: partial collapse of floors and open cracks, width bigger than $25 \mathrm{~mm}$, affecting structural elements.

The second step involves the severity of the recognized damage classified in the first step and the extension of the damage, assuming the edifice being subdivided in three parts. This information can be combined by the use of a matrix [73] to classify the entire structure or infrastructure in eight 
different classes, from no damage to unusable, in order to be comparable with other existing approaches: no damage, negligible, weak, moderate, serious, very serious, potential collapse, and unusable. It is worth noticing that the potential collapse and unusable classes also appear in this final classification.

\subsection{Evaluation and Validation of the Relationship between Vslope Values and Assessed Damage}

To combine and assess the reliability of the remotely collected and on-field data, a symmetric matrix was developed. This matrix was realized considering a possible relationship between the building damage classes and their average Vslope velocities. Four classes of Vslope velocities and four ranks of severity of damage were considered to create a symmetric matrix (Table 2). In this case study, based on the standard deviation, the values of STABILITY were assigned, from 0 to $-4.99 \mathrm{~mm} /$ year, and then Vslope classes were distinguished as LOW (from -5.00 to $-9.99 \mathrm{~mm} /$ year), MEDIUM (from -10.00 to $-19.99 \mathrm{~mm} /$ year) and HIGH (higher than $-20 \mathrm{~mm} /$ year). The choice of the threshold between the classes has to be meaningful, and it has to be set in order to cover all the investigated structures. The classes of damage recorded were grouped in four classes as the Vslope velocities to design a symmetric matrix:

- $\quad$ LOW—o damage and negligible;

- $\quad$ MEDIUM-weak and moderate;

- $\quad$ SEVERE—-severe and very severe;

- $\quad$ HIGH—potential collapse and unusable.

ND (no data) classes were added to both Vslope velocities and damage ranking to identify the structures even if some information is missing.

The outputs of the matrix are 6 classes, depending on the reliability of measurements:

- $\quad$ ND both parameters - no Vslope velocity and damage information;

- $\quad$ ND one parameter - no Vslope velocity or damage information;

- Very low reliability_STABILITY range of Vslope velocities combined with HIGH level of damage or HIGH Vslope velocity combined with LOW level of damage;

- $\quad$ Low reliability-STABILITY range or LOW Vslope velocities combined with SEVERE or HIGH level of damage, respectively, or MEDIUM or HIGH Vslope velocity combined with LOW or MEDIUM level of damage, respectively;

- Medium reliability-STABILITY range, LOW or MEDIUM Vslope velocities combined with MEDIUM, SEVERE or HIGH level of damage, respectively, or LOW, MEDIUM or HIGH Vslope velocity combined with LOW, MEDIUM or SEVERE level of damage, respectively;

- $\quad$ High reliability—only for good correspondence, i.e., STABILITY range of Vslope velocity combined with LOW level of damage, LOW Vslope velocity combined with MEDIUM level of damage, MEDIUM Vslope velocity combined with SEVERE level of damage and HIGH Vslope velocity combined with HIGH level of damage.

This approach helps the interpreters to easily understand where no recorded velocity of displacement by SAR data are strictly related to the detected damage by field surveys. In this way, these outliers, highlighted by very low reliability (green) and low reliability (yellow), can be easily identified in order to singularly analyze and check the reason of discrepancy. In orange and in red are the structures and infrastructure showing medium and high values of reliability, respectively (Table 2). 
Table 2. Reliability matrix of the relationship between Vslope and damage classes.

\begin{tabular}{|c|c|c|c|c|c|}
\hline & ND & LOW Damage & $\begin{array}{c}\text { MEDIUM } \\
\text { Damage }\end{array}$ & $\begin{array}{l}\text { SEVERE } \\
\text { Damage }\end{array}$ & $\begin{array}{c}\text { HIGH } \\
\text { Damage }\end{array}$ \\
\hline \multicolumn{6}{|l|}{ ND } \\
\hline \multicolumn{6}{|l|}{ STABILITY } \\
\hline \multicolumn{6}{|l|}{ LOW Vslope } \\
\hline \multicolumn{6}{|l|}{ MEDIUM } \\
\hline \multicolumn{6}{|l|}{ HIGH Vslope } \\
\hline $\begin{array}{c}\text { High } \\
\text { Reliability }\end{array}$ & \multicolumn{3}{|c|}{$\begin{array}{l}\text { Medium } \\
\text { reliability }\end{array}$} & \multicolumn{2}{|c|}{ Low reliability } \\
\hline $\begin{array}{l}\text { Very Low } \\
\text { Reliability }\end{array}$ & \multicolumn{3}{|c|}{$\begin{array}{c}\text { ND one } \\
\text { parameter }\end{array}$} & \multicolumn{2}{|c|}{$\begin{array}{l}\text { ND both } \\
\text { parameter }\end{array}$} \\
\hline
\end{tabular}

\subsection{Fragility Curves and Damage Probability Map}

A fragility curve is a statistical tool representing the probability of reaching or exceeding a specific damage state severity level $\left(D_{i}\right)$ as a function of a parameter that defines the ground displacement [78]. In other words, it is a way to measure the vulnerability of structures in probabilistic terms.

Fragility curves are mathematically expressed as [54]:

$$
P\left(\text { Damage } \geq D_{i} \mid \Delta\right)=\varnothing\left(\frac{1}{\beta} \cdot \operatorname{Ln}\left(\frac{\Delta}{\overline{\Delta_{l}}}\right)\right)
$$

where $\varnothing(\cdot)$ is the standardized cumulative normal distribution, $\overline{\Delta_{l}}$ and $\beta$ are the median and the standard deviation, respectively, of the natural logarithm of the intensity parameter $\Delta$ for the state of damage $D_{i}$.

In this work, the fragility curves are defined as a Bayesian inference method, in which Equation (3) expresses the a priori probability distribution, and the resulting curve represents the a-posteriori distribution obtained by fitting our data sample with Equation (3). The curves are established to provide a prediction of potential damage on buildings in landslide areas using an empirical (i.e., field observations) method. This method presents the advantage of representing a realistic picture of the actual vulnerability of buildings [79], since they are based on actual recorded damage and measured ground displacements.

Once the damage inventory was collected, the first step to apply the empirical method consists of the classification of the structures based on their structural type (e.g., masonry, reinforced concrete, metal, or timber) and geometrical characteristics (e.g., number of floors). Classifying buildings is a significant factor that has to be considered in developing fragility curves [78]. In the study area, most of the structures are masonry and reinforced concrete type and were considered as a common structural group due to the lack of detailed structural information of the inventoried buildings. Furthermore, they have 1 or 2 floors and thus they can be classified as low-rise buildings according to Hancilar, et al. [80]. The second step consists in the classification of the records corresponding to each structural type according to their observed level of damage $\left(D_{i}\right)$. It is worth noting that the level of damage of the buildings was stated according to the approach in [73]. Then, the InSAR displacements of each building (i.e., the intensity parameter, $\Delta$ ) from each level of damage $\left(D_{i}\right)$ were assigned by means of the Geographical Information System. Finally, for each level of damage $\left(D_{i}\right)$, the parameters that define Equation (1) were calculated and thus the fragility curve could be defined.

To validate and assess the efficiency of the fragility curves, some buildings were singularly positioned in the graph of the fragility curves. Instead, edifices showing a very low reliability between Vslope and damage classes, were plotted and then singularly analysed in order to define the reason of the no-correlation. 
At the end, a damage probability map could be designed according to the relationship provided by the fragility curves for Patigno and Coloretta. Knowing the velocity (Vslope) of the buildings, the probability of damaging could be extracted for all the buildings. By means of an IDW [81,82], the values of damage can be spread and we can create a damage probability maps for the entire hamlets, based on field survey data.

\section{Results}

\subsection{Vslope Deformation Maps}

Vslope allows combining the information collected in both orbits, granting a more precise reconstruction of the real motion component of the displacement affecting Patigno and Coloretta.

In Patigno, the larger landslide affects the village with a movement from NW to SE, and the PS data generally confirm this pattern. ERS1/2 data (Figure 5a), referred to the period July 1992-August 2000, exhibit Vslope velocities higher than $-35 \mathrm{~mm} /$ year in the greater part of the hamlet, with maximum values in its southern portion. In the northern portion of Patigno, the Vslope velocities ranged between the stability range (from 0 to $4.99 \mathrm{~mm} / \mathrm{year}$ ) to $-15 \mathrm{~mm} /$ year. In the southern portion, coinciding with the toe of the landslide that entails the entire built up area, Vslope velocities up to $-56 \mathrm{~mm} /$ year were recorded. The period December 2003-June 2010 covered by ENVISAT data shows a slightly different situation (Figure $5 b$ ) in the northern portion of the hamlet, where Vslope velocities are always lower than $-10 \mathrm{~mm} /$ year. Vslope velocities increase in the central portion of the landslide, with peak values of velocities higher than $-50 \mathrm{~mm} /$ year, while in the southern portion, no PS data were recorded. The COSMO-SkyMed data (Figure 5c), even if available only in ascending orbit, show a higher density in the urbanized area thanks to the X-band resolution. At the same time, the high sensitivity of X-band to vegetation strongly limit the PS density outside of urban areas (e.g., in vegetated areas), where it loses the coherence. The PS data between May 2011 and April 2014 confirmed the velocity distribution of ENVISAT period in the northern portion of Patigno, with Vslope values lower than $-10 \mathrm{~mm} / \mathrm{year}$. The southern portion shows the highest Vslope values up to $-30 \mathrm{~mm} /$ year, with some buildings characterized by very high velocities (up to $-80 \mathrm{~mm} / \mathrm{year}$ ). Due to the presence of high vegetation, no PS data were recorded in the lower portion of the landslide. Sentinel-1 data, spanning between March 2015 and June 2018, confirm the Vslope distribution of the other interferometric products, with velocities increasing from NW to SE, with Vslope passing from $-15 \mathrm{~mm} /$ year in the northern portion of the hamlet, to $-53 \mathrm{~mm} /$ year in the landslide toe area (Figure $5 \mathrm{~d}$ ). Thanks to the processing of the Sentinel-1 data by SqueeSAR data, few points in the lower portion of the hamlet-the toe of the active landslide-were recorded, showing high Vslope velocities.

In summary, the velocity along the slope generally ranges between low values up to more than $-50 \mathrm{~mm} /$ year considering all the sensors. The Vslope velocities show an increment of velocity from the NW to the SE. This general distribution of the PS velocities agrees with the presence of a large mapped active landslide affecting the entire hamlet of Patigno along NW-SE direction. 

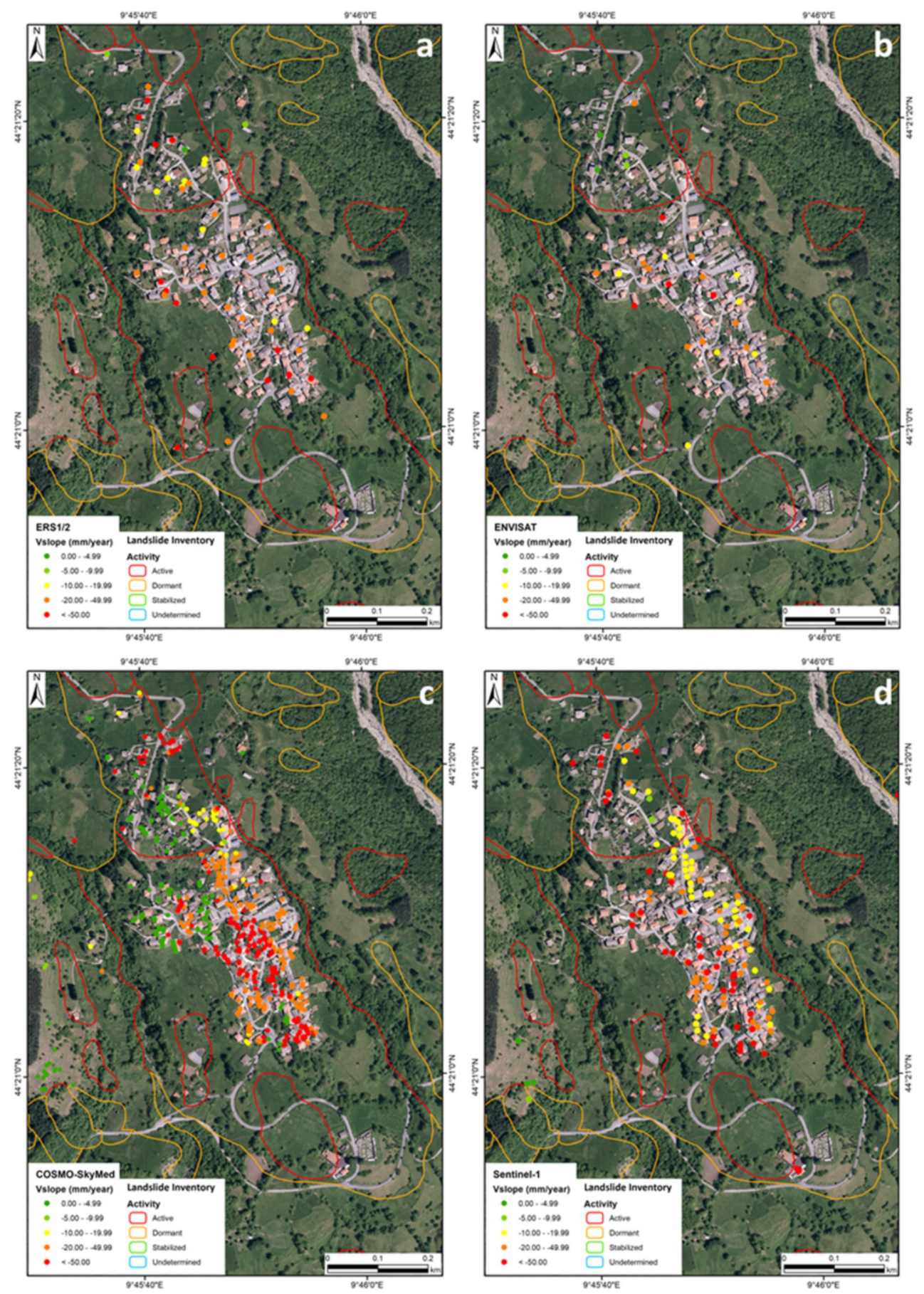

Figure 5. ERS1/2 (a), ENVISAT (b), COSMO-SkyMed (c) and Sentinel-1 (d) deformation map of velocity along the maximum slope for Patigno.

Coloretta does not exhibit a clear spatial trend, but generally the Vslope velocities are higher where active landslides are mapped. For this reason, the areas where higher velocities were recorded are the central and the southeastern portion of the hamlet (Figure 6). 



Figure 6. ERS1/2 (a), ENVISAT (b), COSMO-SkyMed (c) and Sentinel-1 (d) deformation map of velocity along the maximum slope for Coloretta.

In the period of July 1992-August 2000, ERS data show that some mapped landslides affecting the Coloretta hamlet were already active (Figure 6a). High velocities were recorded in the two active landslides involving the central portion of Coloretta, with values ranging between -50 and $-60 \mathrm{~mm} /$ year. Furthermore, high velocities up to $55 \mathrm{~mm} /$ year were recorded in the southern area, where another active landslide was mapped involving the cemetery. ENVISAT data (Figure 6b) showed a general decrease in the Vslope velocities in all the sectors of the Coloretta hamlet. Besides this, the areas mapped as active landslides, in both central and southeastern sectors of the hamlet, show high Vslope velocities. The highest velocities, recorded in the southeastern portion, on the cemetery reach 
-35 mm/year. Between May 2011 and March 2014, the CSK data (Figure 6c) recorder considerable velocities in accordance to older datasets, confirming the stability of the northwestern portions of Patigno. In the central portion of the hamlet, Vslope velocities reach $-40 \mathrm{~mm} / \mathrm{year}$, with peak values of about $-80 \mathrm{~mm} /$ year in the active landslides as well as in the southeastern active landslides involving the cemetery, where Vslope velocities reached values higher than $-45 \mathrm{~mm} /$ year. The more recent data, Sentinel-1 (Figure 6d) confirm the past ground deformation trends showing high velocities in the central and southern portions of Patigno. The area mapped as active landslides continue to show velocities higher than $-30 \mathrm{~mm} /$ year in the central portion of the hamlet and higher than $-20 \mathrm{~mm} /$ year in the southeastern sector. Generally, the stability of the northwestern portion was confirmed also with the recent Sentinel-1 data.

To sum up, Vslope velocities along the slope generally ranges between low values in the northwest portion of the hamlet where dormant landslides are mapped, up to more than $-45 \mathrm{~mm} /$ year recorded by all the sensors in the central and southern areas involved in active landslides. The distribution of the PS velocities agrees with the presence of several known and dormant and active landslide affecting the entire hamlet of Coloretta. All the areas where landslides were not mapped show a general stability, with values lower than $-5 \mathrm{~mm} /$ year for the whole monitored time span.

\subsection{Building Damage Classification Maps}

During three field campaigns, it was possible to collect damage information for 136 and 138 buildings in Patigno and Coloretta hamlets, respectively. Furthermore, 22 ground fractures were recognized and classified (Figure 7a): 14 in Patigno and 8 in Coloretta.

The classification of buildings according to Del Soldato et al. [73] for the Patigno hamlet is reported in Table 3.

Table 3. Classification of the structures of Patigno affected by landslide-induced damage.

\begin{tabular}{cccccccc}
\hline No Damage & Negligible & Weak & Moderate & Severe & Very Severe & Potential Collapse & Unusable \\
\hline 7 & 28 & 35 & 21 & 13 & 9 & 14 & 9 \\
\hline
\end{tabular}

In the potential collapse and unusable classes, we categorized some abandoned structures, but it is necessary to consider that the recorded damage level is a sum of the effect of both the landslide activity and the state and constructive quality of the building.

The highest damaged buildings are in the southern portion of the landslide, along the toe area. It is possible to identify another group of buildings in the center of the Patigno hamlet that was severely damaged or partially collapsed, but mainly abandoned (Figure 7b). In the toe area, both old and new constructions show, at different levels, the effects of the active landslide. The red structures in the southern area, a church and the close cemetery, are totally and partially inaccessible due to the damage severity (Figure 7c,d). The Saint Lorenzo church was historically affected by landslide-induced damage until hydraulic interventions were developed to drain the runoff water by means of two channels. Then, approximatively in the 1980s, the maintenance of these water supply project was abandoned, and the church began again to present severe damage, leading to the interdiction of the church for the safety of population. Furthermore, mainly along the roads, several cracks with relevant steps were recognized (Figure 7e). 


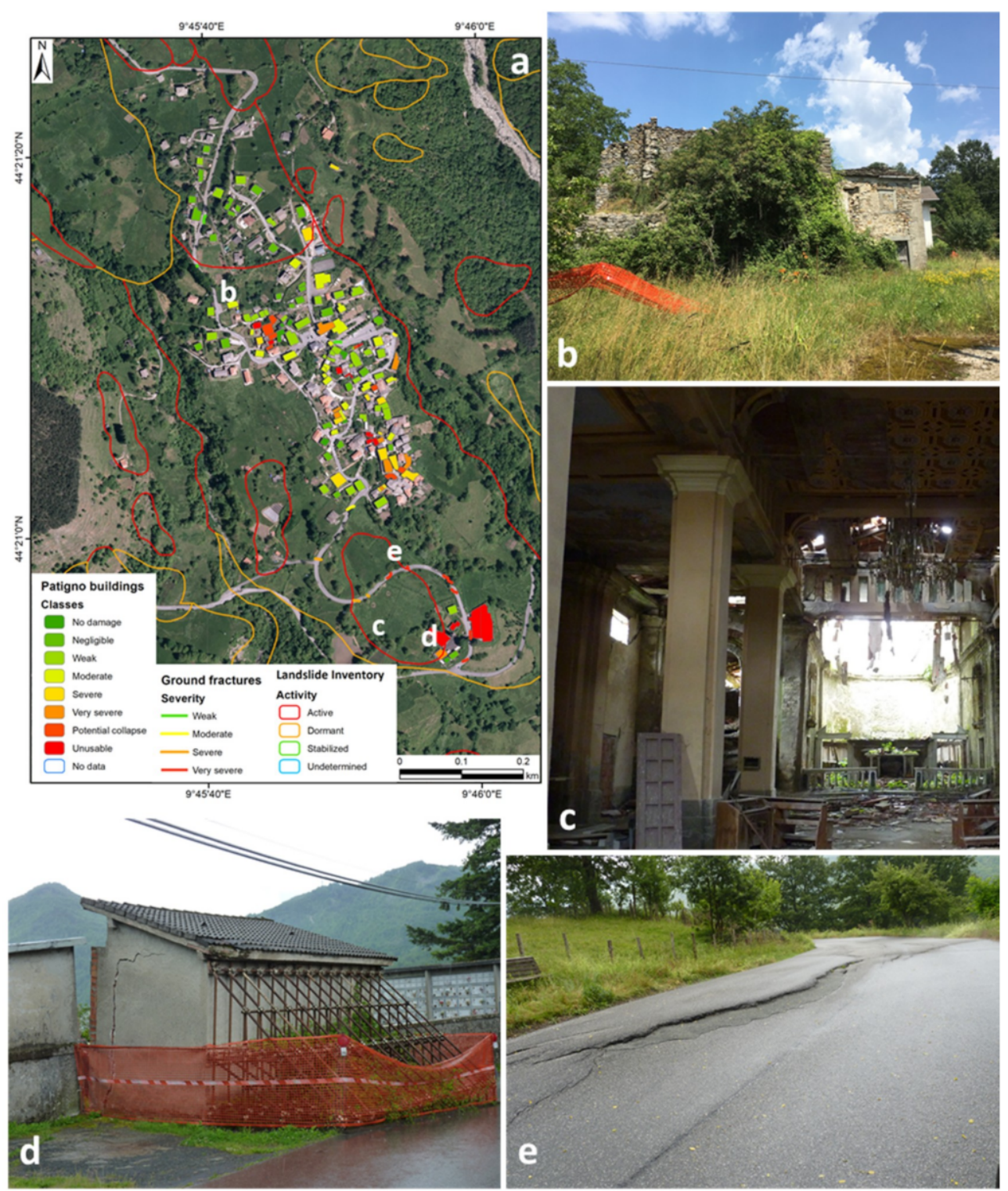

Figure 7. Building damage classification map of Patigno hamlet (a). Different situations can be recognized: a group of buildings abandoned in the center (b); collapsed and highly damaged structures, church and cemetery, at the toe $(\mathbf{c}, \mathbf{d})$; important ground fractures recognizable along a linear infrastructure (i.e., a road) (e).

The damage affecting 138 structures investigated in Coloretta were classified according to Del Soldato et al. [73] classification (Table 4 and Figure 8).

Table 4. Classification of the structures of Coloretta affected by landslide-induced damage.

\begin{tabular}{cccccccc}
\hline No Damage & Negligible & Weak & Moderate & Severe & Very Severe & Potential Collapse & Unusable \\
\hline 6 & 29 & 37 & 26 & 19 & 14 & 5 & 2 \\
\hline
\end{tabular}

The distribution of the different levels of landslide-induced damage recorded (Figure 8a) are generally in accordance to the localization and activity of various mapped landslides. In the northern portion of the hamlet, where dormant landslides are found, few edifices show severe damage and mainly exhibit negligible or weak damage. In the central portion, affected by an active landslide, several structures exhibit moderate or severe damage, and some cracks on the ground are recognizable 
(Figure 8d). The main damaged edifices can be found in the southeastern region of the hamlet. In this area, several buildings show severe or very severe conditions and also relevant ground fractures can be recognized. In particular, a tower in a square shows an important tilting, approximatively higher than 5 degrees with respect to the vertical (Figure 8b), while the Saint Rocco church, close to the tower, registers multiple open cracks and fractures in addition to a visible distortion of the arch between the nave and the apse (Figure 8c).

Severe damage was recognized also in the cemetery (see circle in Figure 8a), where relevant and open cracks on the structures and on the ground were.

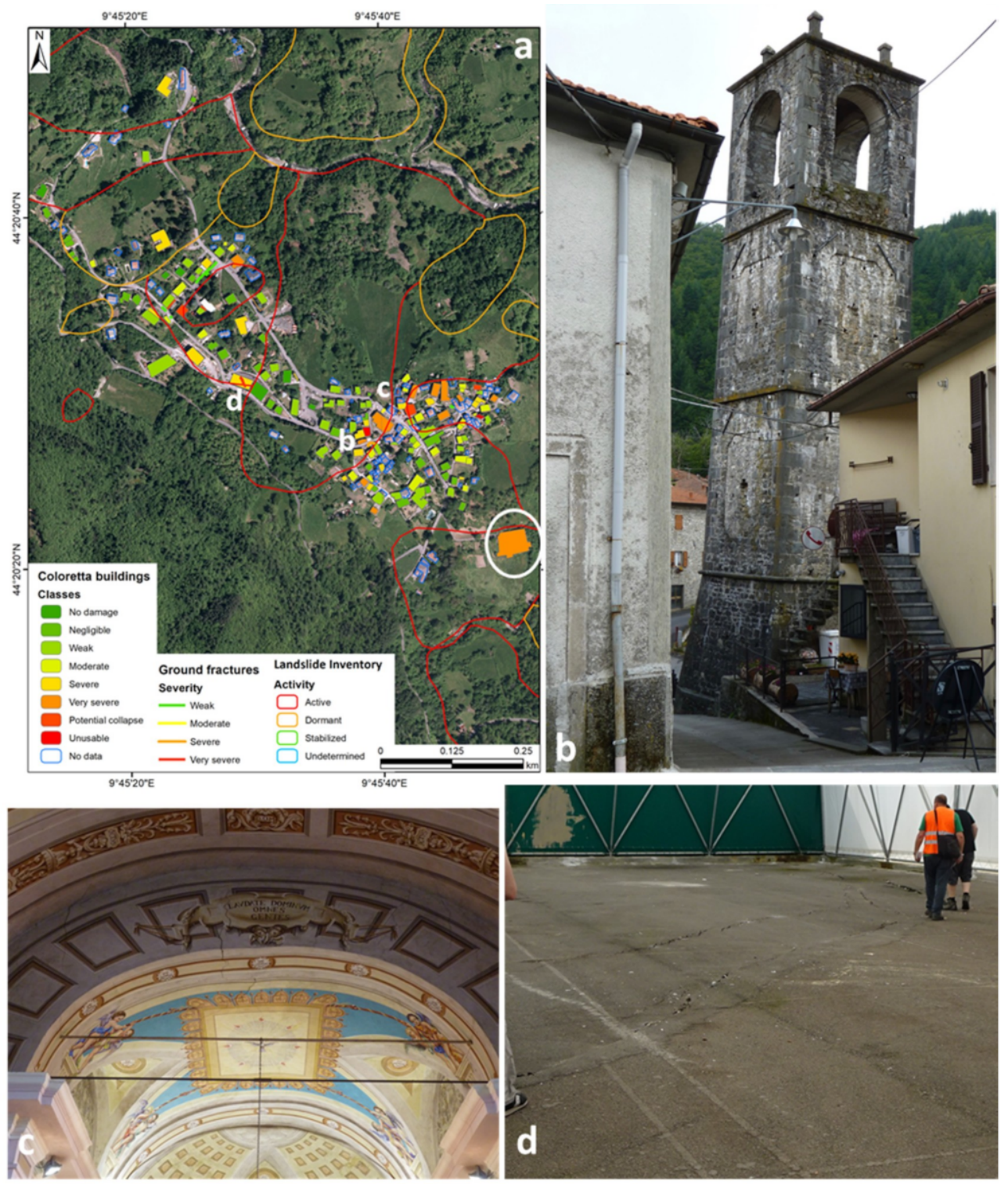

Figure 8. Building damage classification map of Coloretta hamlet (a). Different situations can be recognized: a tilted structure in the center (b); significant fractures on structural elements of edifices (c); and relevant ground fractures: sidewalk and pavements $(\mathbf{d})$.

\subsection{Vslope-Damage Assessment}

To evaluate a possible correlation between Vslope velocities recorded by SAR satellite data and the classes of damage, a reliability matrix was applied to both the Patigno and Coloretta hamlets (Figure 9). In both cases, the correlation shows a medium to high reliability in general and only for few localized structures a bad correlation (low and very low reliability). Structures with very low reliability were not 
included in the fragility curves approach and they will be singularly investigated, since they could be abandoned buildings or recently built or renewed edifices.

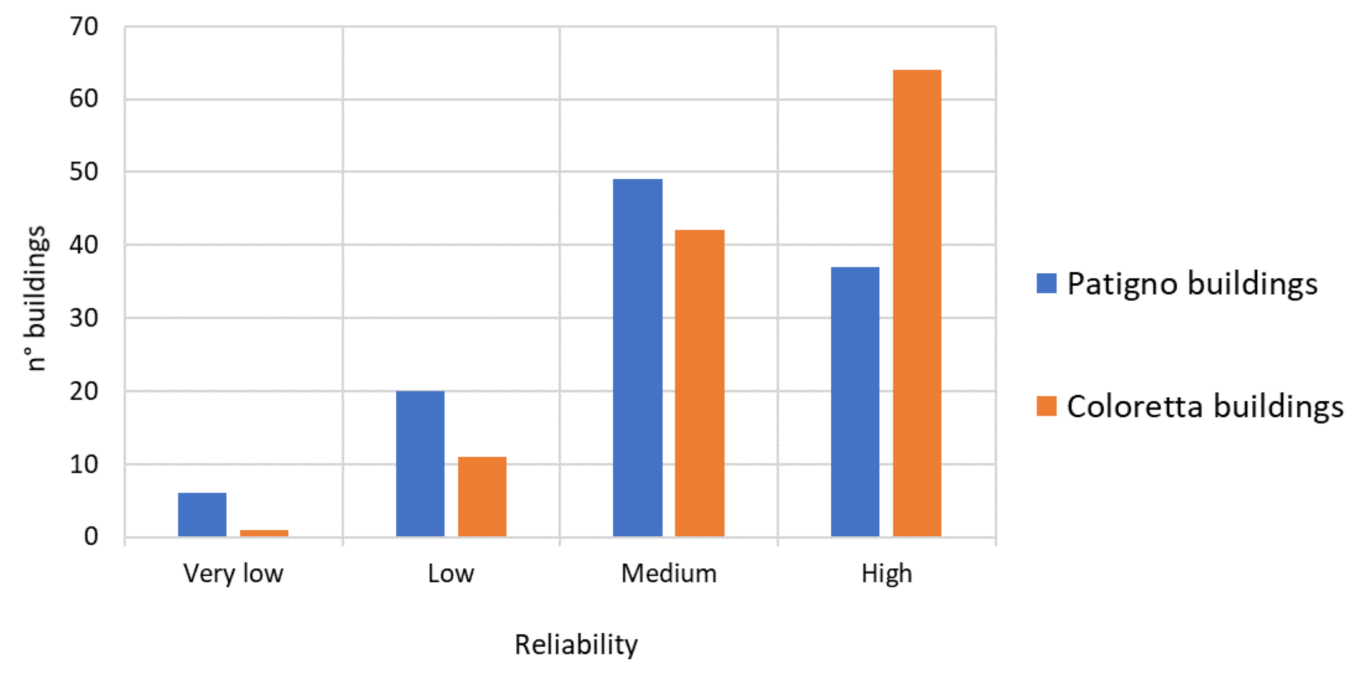

Figure 9. Building classification of both Patigno (in blue) and Coloretta (in orange) hamlets of the reliability between damage and Vslope classes.

\subsection{Landslide-Induced Damage Probability Maps}

In order to look for a probabilistic relation between the Vslope velocities and the identified and classified damage, the fragility curves were derived for Patigno and Coloretta hamlets. The curves were defined using only the parameters collected on the structures with low to high reliability. Furthermore, with this approach it was possible to assess the landslide-induced damage probability maps. To this aim, the dataset of damaged buildings was divided into: (i) training set, used for calibrating the fragility curves; and (ii) test dataset, used for validating the fragility curves defined in a). For the test dataset, at least one, when possible two, edifices for each damage classes were selected. This procedure was separately conducted for the two hamlets, considering the different characteristics of the landslide in term of spatial distribution and volume.

Both curves of Patigno (Figure 10a) and Coloretta (Figure 10b) resulted in validation, and the buildings with very low correlation, outliers (red points in Figure 9), were singularly analyzed in order to understand the reason for this non-correlation. The damage probability maps for Patigno (Figure 10c) and Coloretta (Figure 10d) hamlets were then derived as smoothly as possible, by means of the interpolation of the extracted values for the investigated building. 

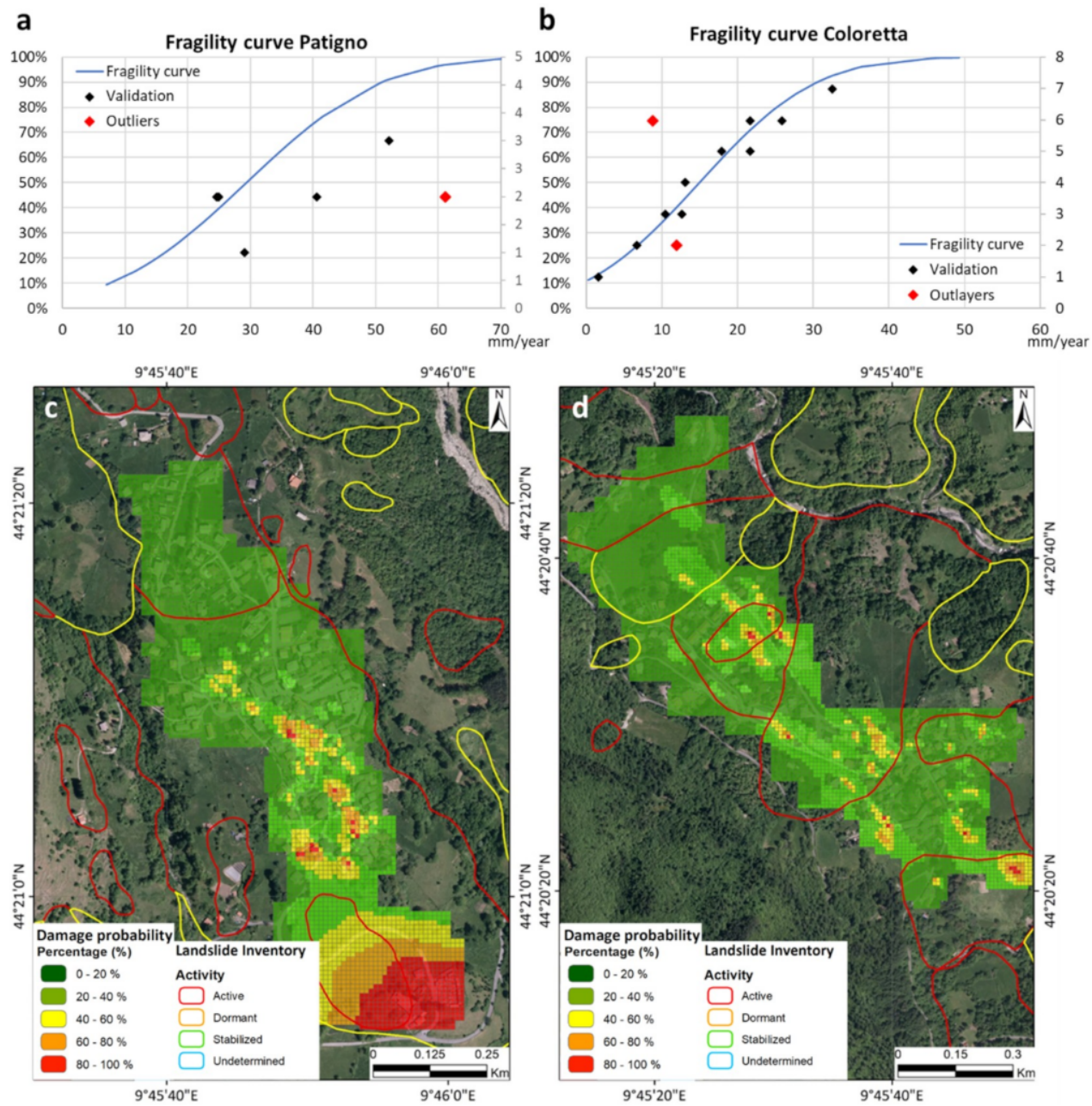

Figure 10. Fragility curves and derived damage probability maps derived for both Patigno (a,c, respectively) and Coloretta (b,d, respectively).

The assessed landslide-induced damage probability maps assume that the Vslope velocity is not changing too much over time and no abrupt accelerations occur. The results can be useful for administrative offices and civil protection entities for identifying those areas where structures could be damaged. The Patigno landslide-induced damage probability map (Figure 10c) shows a similar situation with respect to the Vslope velocity map with areas with no, or very low probability in the norther portion increasing along the south. It can be virtually divided in three areas:

- $\quad$ the northern portion of the hamlet with no or very low probability of damage (0-20\%);

- the central portion where the probability shows different values localized areas with high probability of damage within a general low rate;

- $\quad$ the southern with generally high values of probability of damage (60-100\%).

The Coloretta landslide-induced damage probability map (Figure 10d) shows a general low probability with some localized areas with high values of building damage probability. These areas are localized, in the central or, mainly, in the southeastern sector. It is interesting to notice that quite all the high values of damage probability are located into mapped active landslides. Some exceptions are in the southeastern portion of the hamlets, where the damage probability shows two localized average to high values, even if no landslides were mapped. 


\section{Discussions}

The instabilities affecting the areas of interest of the Patigno and Coloretta hamlets were poorly investigated in the past, as well as their effects on structures and infrastructure. Only field surveys and traditional approaches were conducted on a portion of one of the sites under investigation, while advanced techniques and more recent data were used in this work [69-71]. The SAR data contribution results were significant for an easier and quicker mapping of landslide-prone areas. This type of investigation allows for collecting plenty of information for ground deformations detection and land managing. As a consequence, it helps for making decisions about the priority actions to fulfill in order to avoid the occurrence or the recurrence of damaging events and consequences on structures and infrastructures.

A-DInSAR analyses and damage classification by field surveys over two hamlets, Patigno and Coloretta, in the Tuscany Northern Apennines (central Italy) were carried out in order to create damage probability maps at a local scale. These products can be very useful for the local administrator for urban planning and management, as well as to identify areas with higher potentiality of damage on structures and to optimize the damage assessment field campaigns. It could be a relevant support for small cities, since a full and continuous damage survey would require human and economic resources, that is sometimes a difficult task for small mountain municipalities.

We have to consider that the A-DInSAR approach has some limitations, mainly for mountainous areas as Zery municipality, due to the morphology and the aspect of the slopes. An underestimation of the real motion component can occur if the LOS direction diverges too much from the direction of a landslide. In this case, the exposition of the slopes of Patigno and Coloretta are mainly E-SE and E-NE, respectively (Figure S1a). Another factor that can create underestimation is the slope gradient. In both areas, the local slope angle is generally between $5^{\circ}$ and $15^{\circ}$ (Figure S1b). To have an overall idea about the underestimation in the investigated area the $\mathrm{C}$ index maps for both ascending and descending datasets (Figure S2a,b, respectively) were calculated. The maps show that in the ascending orbit, 60 to 80 percent of the real component of motion could be estimated in both Patigno and Coloretta. In the descending orbit, the velocities could be underestimated, mainly in Coloretta, where less the $40 \%$ of the real motion component could be measured. To partially solve the underestimation related to LOS velocities, we reconstructed with good approximation the real component along the maximum slope using the Vslope method. This approach, used by many authors for landslide monitoring, can be supported and validated by in situ measurements, if available e.g., [83-86].

In this work, building damage was considered as a direct consequence of the long-term motion of a landslide, being a main body as in the case of Patigno, or a multiple sliding surfaces as in the case of Coloretta. In this sense, Vslope velocity is a good indicator of the landslide movement, and thus of building damage if buildings with similar constructive characteristics are selected. In both areas, the largest part of structures is 2-3 floors of masonry building, and few reinforced concrete buildings are present. More detailed building information about foundations or constructive quality could not be gathered at this stage, requiring single building structural inspections.

It is interesting to note that only by the simple comparison between Vslope velocities and building classification maps, a rough correlation is recognizable (clearer for the Patigno hamlet). In general, the distribution of the damaged buildings seems to follow the velocity distribution and be connected to the known state of activity of landslides.

Even if fragility curves were separately designed for Patigno and Coloretta, several edifices were used to validate the results, and some outliers were identified. All of them were singularly analyzed by further dedicated field surveys, and two opposite reasons for bad correlation between Vslope velocities and damage classes could be recognized:

- buildings abandoned that can be classified rightly as un-inhabitable (higher class of damage) but can be in a stable area. In this case, the correlation between the damage level and the Vslope velocity classes results very low (Figure 11) due to the intensity of the fractures and cracks; 
- new or restored constructions that show no cracks or negligible damage, that can be located in areas with recorded medium or high velocities. Even if high Vslope velocities are registered, these are not sufficient to have sudden visible consequences on new or restored structures. In these cases, the correlation between the damage and the Vslope classes results in very low to low.
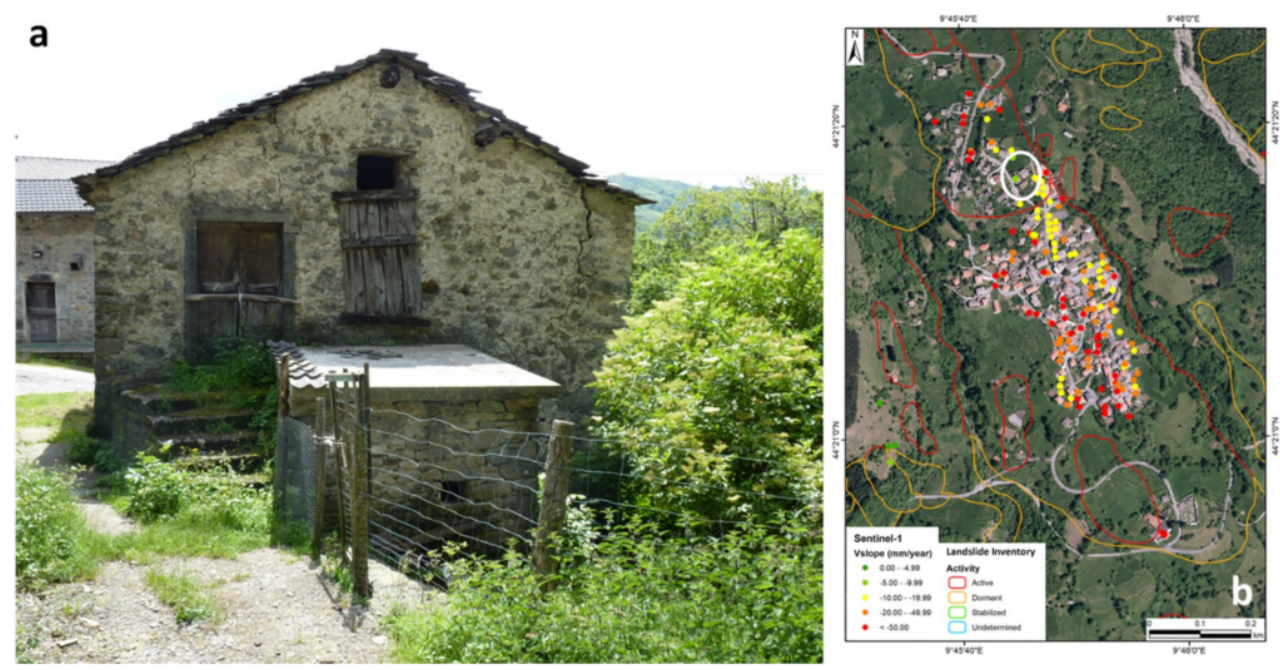

Figure 11. Abandoned edifices (a), classified as damaged, in the northern portion of the hamlet where the Vslope are values lower than $-10 \mathrm{~mm} /$ year (with circle in $\mathbf{b}$ ).

As a general matter, the probability of reaching or exceeding a level of damage with respect to the ground deformation designed by the fragility curves was satisfying.

The probability damage maps, final products of this work, for both Patigno and Coloretta were calculated according to the fragility curve approach. Some problems relating to the low number of structures could be recognized, for example, in the southwestern portion of Patigno, where the effect of the interpolation used for designing the probability maps was highly influenced by the few edifices strongly damaged: the Saint Lorenzo church and the nearby cemetery.

The resulting map can be very useful for local administrator and civil protection entities in case of further events, reactivations or continuous motion of the landslide to evaluate potentially damaged areas using new A-DInSAR datasets and the calibrated fragility curves. It is worth noting that the usefulness of the designed damage probability map derives the use of calibrated and validated fragility curves. However, these maps have some uncertainties due to several factors that should be taken into consideration:

- $\quad$ they do not consider the different load-bearing structure of the buildings; this factor is expeditiously evaluated only during the damage level survey;

- the damage classification is referred to the full life of the buildings that, generally, is different with respect to the monitored period;

- the activity, direction, number of the landslides affecting the area of interest, as well as their typology (e.g., rotational, sliding, etc.)

- considering the C-band resolution for each building, it is sometimes not possible to have more than one or two PSs for building. For this reason, differential motions for single buildings were not easily detected.

Besides these limitations, the maps generally reflect the real situation of the areas affected by landslides. In fact, a good correspondence can be recognized between the recorded damage collected during the field surveys and the know active and dormant landslides, following their morphology. 
In the Region of Tuscany, a continuous monitoring service based on Sentinel-1 data provides velocity maps every 12 days updated [87]. This data availability allows in the future the frequent update of fragility curves and the derived damage probability maps, following the evolution of ground displacements.

An important improvement of this work, and a further development would be to analyze the increment of the damage in the same time span of the available SAR data. In this way, the precision of the probability damage map could improve significantly.

\section{Conclusions}

In this work, an analysis of remote-sensing SAR data and landslide-induced damage affecting the structures of two hamlets in Northern Tuscany (central Italy) was conducted. Furthermore, the combination of the results and the possible relationship between them was investigated in order to design damage probability maps as accurately as possible, using fragility curves derived from recorded damage and Vslope velocities data.

The Patigno hamlet, affected by a large deep-seated landslide and few other minor active landslides, registered high velocities with severe damage recorded by buildings in its southern portion. The obtained results are in accordance with the situation recorded by field survey, the morphology of the landslide and the recorded velocity, showing the main activity of the southern portion of the landslide. In addition, the information recorded on the edifices, by field surveys and satellite interferometry, helped defining areas more prone to damage if the motion were to last or accelerate.

The probability damage map assessed for the Coloretta hamlet shows different damage sectors because of the numerous landslides affecting the edifices, differently characterized by activity and velocity of displacement. In this case, the application of the fragility curves for designing the probability damage map resulted were more effective in identifying possible landslide damaging areas as well as safer zones.

Besides some limitations, the damage probability maps designed for Patigno and Coloretta hamlets were coherent with the real situation recognized during the field surveys, with the exception of some particular outliers, abandoned or new constructions, which were then singularly analysed.

Knowing the areas where the edifices are highly prone to be damaged can be important for the local authorities. The damage probability maps can be useful for helping them to highlight landslide-induced damage-prone areas and safer sectors. These products, combined with the use of the deformation map, can help the local administrators for better managing the territory.

The methodology for assessing areas with structures prone to be damaged by ground deformations applied for the Patigno and Coloretta hamlets could be applied in wider regions and in areas affected by different geohazards recognizable by InSAR analysis (e.g., land subsidence) and promises satisfying results.

Supplementary Materials: The following are available online at http://www.mdpi.com/2072-4292/11/12/1486/s1, Figure S1: Aspect (a) and Slope (b) of the area of interest, Figure S2: C index maps for both ascending (a) and descending (b) Sentinel-1 datasets.

Author Contributions: M.D.S. designed the work and wrote the manuscript; M.D.S., F.P., and R.T. performed the data analysis; L.S. and F.R. helped in the results interpretation and revised the final version of the paper; R.F. and N.C. supervised the entire project.

Funding: The APC was funded by the Regional government of Tuscany, under the agreement "Monitoring ground deformation in the Tuscany Region with satellite radar data".

Acknowledgments: This work has been carried out within the project founded and supported by the Regional government of Tuscany, under the agreement "Monitoring ground deformation in the Tuscany Region with satellite radar data". Roberto Tomás was supported by the Spanish Ministry of Economy, Industry and Competitiveness (MINECO), the State Agency of Research (AEI) and European Funds for Regional Development (FEDER), under projects TEC2017-85244-C2-1-P and PRX17/00439.

Conflicts of Interest: The authors declare no conflict of interest. 


\section{References}

1. Herrera, G.; Mateos, R.M.; García-Davalillo, J.C.; Grandjean, G.; Poyiadji, E.; Maftei, R.; Filipciuc, T.-C.; Auflič, M.J.; Jež, J.; Podolszki, L. Landslide databases in the Geological Surveys of Europe. Landslides 2018, 15, 359-379. [CrossRef]

2. Bogaard, T.A.; Greco, R. Landslide hydrology: From hydrology to pore pressure. Wiley Interdiscip. Rev. Water 2016, 3, 439-459. [CrossRef]

3. Tanyaş, H.; van Westen, C.J.; Allstadt, K.E.; Jibson, R.W. Factors controlling landslide frequency-area distributions. Earth Surf. Process. Landf. 2019, 44, 900-917. [CrossRef]

4. Gariano, S.L.; Guzzetti, F. Landslides in a changing climate. Earth-Sci. Rev. 2016, 162, 227-252. [CrossRef]

5. Segoni, S.; Piciullo, L.; Gariano, S.L. A review of the recent literature on rainfall thresholds for landslide occurrence. Landslides 2018, 15, 1483-1501. [CrossRef]

6. Jaboyedoff, M.; Michoud, C.; Derron, M.-H.; Voumard, J.; Leibundgut, G.; Sudmeier-Rieux, K.; Nadim, F.; Leroi, E. Human-induced landslides: Toward the analysis of anthropogenic changes of the slope environment. In Landslides and Engineered Slopes. Experience, Theory and Practice; CRC Press: Boca Raton, FL, USA, 2018; pp. 217-232.

7. Godt, J.; Coe, J.; Savage, W. Relation between cost of damaging landslides and construction age, Alameda County, California, USA, El Niño winter storm season, 1997-1998. In Proceedings of the 8th International Symposium on Landslides, Cardiff, Wales, 26-30 June 2000; pp. 26-30.

8. Schuster, R.L.; Fleming, R.W. Economic losses and fatalities due to landslides. Bull. Assoc. Eng. Geol. 1986, 23, 11-28. [CrossRef]

9. Schuster, R.L. Socioeconomic significance of landslides. Landslides: Investigation and Mitigation; Transportation Research Board Special Report; National Academy Press: Washington, DC, USA, 1996; Volume 247, pp. $12-35$.

10. Haque, U.; Blum, P.; Da Silva, P.F.; Andersen, P.; Pilz, J.; Chalov, S.R.; Malet, J.-P.; Auflič, M.J.; Andres, N.; Poyiadji, E. Fatal landslides in Europe. Landslides 2016, 13, 1545-1554. [CrossRef]

11. Moore, R.; McInnes, R. The impacts of landslides on global society: Planning for change. Landslides and engineered slopes: Experience, theory and practice. In Proceedings of the 12th International Symposium on Landslides, Napoli, Italy, 12-19 June 2016; pp. 1461-1468.

12. Petley, D. Global patterns of loss of life from landslides. Geology 2012, 40, 927-930. [CrossRef]

13. Goetz, J.N.; Guthrie, R.H.; Brenning, A. Integrating physical and empirical landslide susceptibility models using generalized additive models. Geomorphology 2011, 129, 376-386. [CrossRef]

14. Gullà, G.; Peduto, D.; Borrelli, L.; Antronico, L.; Fornaro, G. Geometric and kinematic characterization of landslides affecting urban areas: The Lungro case study (Calabria, Southern Italy). Landslides 2017, 14, 171-188. [CrossRef]

15. Guzzetti, F.; Mondini, A.C.; Cardinali, M.; Fiorucci, F.; Santangelo, M.; Chang, K.-T. Landslide inventory maps: New tools for an old problem. Earth-Sci. Rev. 2012, 112, 42-66. [CrossRef]

16. Van Westen, C.J. Remote sensing and GIS for natural hazards assessment and disaster risk management. Treatise Geomorphol. 2013, 3, 259-298.

17. Corominas, J.; Moya, J.; Lloret, A.; Gili, J.; Angeli, M.; Pasuto, A.; Silvano, S. Measurement of landslide displacements using a wire extensometer. Eng. Geol. 2000, 55, 149-166. [CrossRef]

18. Zhang, Y.; Tang, H.; Li, C.; Lu, G.; Cai, Y.; Zhang, J.; Tan, F. Design and testing of a flexible inclinometer probe for model tests of landslide deep displacement measurement. Sensors 2018, 18, 224. [CrossRef] [PubMed]

19. Li, Y.; Huang, J.; Jiang, S.-H.; Huang, F.; Chang, Z. A web-based GPS system for displacement monitoring and failure mechanism analysis of reservoir landslide. Sci. Rep. 2017, 7, 17171. [CrossRef] [PubMed]

20. Colesanti, C.; Ferretti, A.; Prati, C.; Rocca, F. Monitoring landslides and tectonic motions with the Permanent Scatterers Technique. Eng. Geol. 2003, 68, 3-14. [CrossRef]

21. Cotecchia, V.; Grassi, D.; Merenda, L. Fragilità dell'area urbana occidentale di Ancona dovuta a movimenti di massa profondi e superficiali ripetutisi nel 1982. Geol. Appl. Idrogeol. 1995, 30, 633-657.

22. Glenn, N.F.; Streutker, D.R.; Chadwick, D.J.; Thackray, G.D.; Dorsch, S.J. Analysis of LiDAR-derived topographic information for characterizing and differentiating landslide morphology and activity. Geomorphology 2006, 73, 131-148. [CrossRef]

23. Jaboyedoff, M.; Oppikofer, T.; Abellán, A.; Derron, M.-H.; Loye, A.; Metzger, R.; Pedrazzini, A. Use of LIDAR in landslide investigations: A review. Nat. Hazards 2012, 61, 5-28. [CrossRef] 
24. Bovenga, F.; Wasowski, J.; Nitti, D.; Nutricato, R.; Chiaradia, M. Using COSMO/SkyMed X-band and ENVISAT C-band SAR interferometry for landslides analysis. Remote Sens. Environ. 2012, 119, 272-285. [CrossRef]

25. Crosetto, M.; Monserrat, O.; Cuevas-González, M.; Devanthéry, N.; Crippa, B. Persistent scatterer interferometry: A review. ISPRS J. Photogramm. Remote Sens. 2016, 115, 78-89. [CrossRef]

26. Del Soldato, M.; Riquelme, A.; Bianchini, S.; Tomàs, R.; Di Martire, D.; De Vita, P.; Moretti, S.; Calcaterra, D. Multisource data integration to investigate one century of evolution for the Agnone landslide (Molise, southern Italy). Landslides 2018, 15, 2113-2128. [CrossRef]

27. Tofani, V.; Raspini, F.; Catani, F.; Casagli, N. Persistent Scatterer Interferometry (PSI) technique for landslide characterization and monitoring. Remote Sens. 2013, 5, 1045-1065. [CrossRef]

28. Bianchini, S.; Raspini, F.; Solari, L.; Del Soldato, M.; Ciampalini, A.; Rosi, A.; Casagli, N. From Picture to Movie: Twenty Years of Ground Deformation recording over Tuscany Region (Italy) with Satellite InSAR. Front. Earth Sci. 2018, 6, 177. [CrossRef]

29. Tomás, R.; Li, Z. Earth Observations for Geohazards: Present and Future Challenges; Multidisciplinary Digital Publishing Institute: Basel, Switzerland, 2017.

30. Del Soldato, M.; Farolfi, G.; Rosi, A.; Raspini, F.; Casagli, N. Subsidence Evolution of the Firenze-Prato-Pistoia Plain (Central Italy) Combining PSI and GNSS Data. Remote Sens. 2018, 10, 1146. [CrossRef]

31. Nobile, A.; Dille, A.; Monsieurs, E.; Basimike, J.; Bibentyo, T.; d'Oreye, N.; Kervyn, F.; Dewitte, O. Multi-temporal DInSAR to characterise landslide ground deformations in a tropical urban environment: Focus on Bukavu (DR Congo). Remote Sens. 2018, 10, 626. [CrossRef]

32. Novellino, A.; Cigna, F.; Sowter, A.; Ramondini, M.; Calcaterra, D. Exploitation of the Intermittent SBAS (ISBAS) algorithm with COSMO-SkyMed data for landslide inventory mapping in north-western Sicily, Italy. Geomorphology 2017, 280, 153-166. [CrossRef]

33. Bardi, F.; Raspini, F.; Frodella, W.; Lombardi, L.; Nocentini, M.; Gigli, G.; Morelli, S.; Corsini, A.; Casagli, N. Monitoring the rapid-moving reactivation of Earth flows by means of GB-InSAR: The April 2013 Capriglio Landslide (Northern Appennines, Italy). Remote Sens. 2017, 9, 165. [CrossRef]

34. Del Soldato, M.; Riquelme, A.; Tomás, R.; De Vita, P.; Moretti, S. Application of structure from motion photogrammetry to multi-temporal geomorphological analyses: Case studies from Italy and Spain. Geogr. Fis. E Din. Quat. 2018, 41, 51-66.

35. Fiorucci, F.; Giordan, D.; Santangelo, M.; Dutto, F.; Rossi, M.; Guzzetti, F. Criteria for the optimal selection of remote sensing optical images to map event landslides. Nat. Hazards Earth Syst. Sci. 2018, 18, 405-417. [CrossRef]

36. Stumpf, A.; Malet, J.-P.; Delacourt, C. Correlation of satellite image time-series for the detection and monitoring of slow-moving landslides. Remote Sens. Environ. 2017, 189, 40-55. [CrossRef]

37. Casagli, N.; Frodella, W.; Morelli, S.; Tofani, V.; Ciampalini, A.; Intrieri, E.; Raspini, F.; Rossi, G.; Tanteri, L.; $\mathrm{Lu}, \mathrm{P}$. Spaceborne, UAV and ground-based remote sensing techniques for landslide mapping, monitoring and early warning. Geoenviron. Disasters 2017, 4, 9. [CrossRef]

38. Rossi, G.; Tanteri, L.; Tofani, V.; Vannocci, P.; Moretti, S.; Casagli, N. Multitemporal UAV surveys for landslide mapping and characterization. Landslides 2018, 1-8. [CrossRef]

39. Turner, D.; Lucieer, A.; de Jong, S. Time series analysis of landslide dynamics using an unmanned aerial vehicle (UAV). Remote Sens. 2015, 7, 1736-1757. [CrossRef]

40. Tomás, R.; Romero, R.; Mulas, J.; Marturià, J.J.; Mallorquí, J.J.; López-Sánchez, J.M.; Herrera, G.; Gutiérrez, F.; González, P.J.; Fernández, J. Radar interferometry techniques for the study of ground subsidence phenomena: A review of practical issues through cases in Spain. Environ. Earth Sci. 2014, 71, 163-181. [CrossRef]

41. Crosetto, M.; Biescas, E.; Duro, J.; Closa, J.; Arnaud, A. Generation of advanced ERS and Envisat interferometric SAR products using the stable point network technique. Photogramm. Eng. Remote Sens. 2008, 74, 443-450. [CrossRef]

42. Joyce, K.; Samsonov, S.; Levick, S.R.; Engelbrecht, J.; Belliss, S. Mapping and monitoring geological hazards using optical, LiDAR, and synthetic aperture RADAR image data. Nat. Hazards 2014, 73, 137-163. [CrossRef]

43. Solari, L.; Raspini, F.; Del Soldato, M.; Bianchini, S.; Ciampalini, A.; Ferrigno, F.; Tucci, S.; Casagli, N. Satellite radar data for back-analyzing a landslide event: The Ponzano (Central Italy) case study. Landslides 2018, 15, 773-782. [CrossRef] 
44. Corominas, J.; van Westen, C.; Frattini, P.; Cascini, L.; Malet, J.-P.; Fotopoulou, S.; Catani, F.; Van Den Eeckhaut, M.; Mavrouli, O.; Agliardi, F. Recommendations for the quantitative analysis of landslide risk. Bull. Eng. Geol. Environ. 2014, 73, 209-263. [CrossRef]

45. Geudtner, D.; Torres, R.; Snoeij, P.; Davidson, M.; Rommen, B. Sentinel-1 System capabilities and applications. In Proceedings of the IGARSS, Munich, Germany, 22-27 June 2012; pp. 1457-1460.

46. Torres, R.; Snoeij, P.; Geudtner, D.; Bibby, D.; Davidson, M.; Attema, E.; Potin, P.; Rommen, B.; Floury, N.; Brown, M. GMES Sentinel-1 mission. Remote Sens. Environ. 2012, 120, 9-24. [CrossRef]

47. Rybár, J. Increasing impact of anthropogenic activities upon natural slope stability. In Proceedings of the International Symposium on Engineering Geology and the Environment, Athens, Greece, 23-27 June 1997; pp. 23-27.

48. Chiocchio, C.; Iovine, G.; Parise, M. A proposal for surveying and classifying landslide damage to buildings in urban areas. Processing of the International Symposium on Engineering Geology and the Environment, Athens, Greece, 23-27 June 1997.

49. Alexander, D. Landslide damage to buildings. Environ. Geol. Water Sci. 1986, 8, 147-151. [CrossRef]

50. Fotopoulou, S.; Pitilakis, K. Fragility curves for reinforced concrete buildings to seismically triggered slow-moving slides. Soil Dyn. Earthq. Eng. 2013, 48, 143-161. [CrossRef]

51. Mavrouli, O.; Fotopoulou, S.; Pitilakis, K.; Zuccaro, G.; Corominas, J.; Santo, A.; Cacace, F.; De Gregorio, D.; Di Crescenzo, G.; Foerster, E. Vulnerability assessment for reinforced concrete buildings exposed to landslides. Bull. Eng. Geol. Environ. 2014, 73, 265-289. [CrossRef]

52. Negulescu, C.; Foerster, E. Parametric studies and quantitative assessment of the vulnerability of a RC frame building exposed to differential settlements. Nat. Hazards Earth Syst. Sci. 2010, 10, 1781-1792. [CrossRef]

53. Negulescu, C.; Ulrich, T.; Baills, A.; Seyedi, D. Fragility curves for masonry structures submitted to permanent ground displacements and earthquakes. Nat. Hazards 2014, 74, 1461-1474. [CrossRef]

54. Peduto, D.; Ferlisi, S.; Nicodemo, G.; Reale, D.; Pisciotta, G.; Gullà, G. Empirical fragility and vulnerability curves for buildings exposed to slow-moving landslides at medium and large scales. Landslides 2017, 14, 1993-2007. [CrossRef]

55. Peduto, D.; Nicodemo, G.; Maccabiani, J.; Ferlisi, S. Multi-scale analysis of settlement-induced building damage using damage surveys and DInSAR data: A case study in The Netherlands. Eng. Geol. 2017, 218, 117-133. [CrossRef]

56. Saeidi, A.; Deck, O.; Verdel, T. Development of building vulnerability functions in subsidence regions from empirical methods. Eng. Struct. 2009, 31, 2275-2286. [CrossRef]

57. Peel, M.C.; Finlayson, B.L.; McMahon, T.A. Updated world map of the Köppen-Geiger climate classification. Hydrol. Earth Syst. Sci. Discuss. 2007, 4, 439-473. [CrossRef]

58. Feroni, A.C.; Leoni, L.; Martelli, L.; Martinelli, P.; Ottria, G.; Sarti, G. The Romagna Apennines, Italy: An eroded duplex. Geol. J. 2001, 36, 39-54. [CrossRef]

59. Elter, P.; Schwab, K. Nota illustrativa della carta geologica all'1: 50.000 della zona di Carro-Zeri-Pontremoli. Boll. Soc. Geol. Ital 1959, 78, 157-188.

60. Federici, P.; Puccinelli, A.; Chelli, A.; D'Amato Avanzi, G.; Ribolini, A.; Verani, M. La grande frana di Patigno di Zeri (Massa-Carrara). Mem. Della Accad. Lunigianese Di Sci. Giovanni Capellini. Sci. Nat. Fis. E Mat. 2000, 70, 3-51.

61. Chelli, A.; Stefanini, M.C. Geomorphological Features and Temporal Distribution of the Present-day Landslides Activity in the High Gordana Basin (Zeri, Northern Apennines): A Dendrogeomorphological Anlysis. Comitato Glaciologico Italiano 1999, 22, 105-114.

62. Baldi, P.; Cenni, N.; Fabris, M.; Zanutta, A. Kinematics of a landslide derived from archival photogrammetry and GPS data. Geomorphology 2008, 102, 435-444. [CrossRef]

63. Raiti, R.; Signanini, P.; Torrese, P.; Sammartino, P. II metodo della ricollocazione nella risoluzione di problematiche geologicoambientali: Il caso di Zeri (Massa-Carrara). G. Di Geol. Appl. 2006, 3, 213-220.

64. Portale Cartografico Nazionale (PCN) of the Italian Ministry for the Environment, Territory and Sea (METS). Available online: http://www.pcn.minambiente.it/ (accessed on 15 May 2019).

65. Interferometric SAR satellite website of the Region of Tuscany. Available online: https://geoportale.lamma. rete.toscana.it/difesa_suolo/ (accessed on 15 May 2019).

66. Ferretti, A.; Prati, C.; Rocca, F. Permanent scatterers in SAR interferometry. Geosci. Remote Sens. IEEE Trans. 2001, 39, 8-20. [CrossRef] 
67. Ferretti, A.; Prati, C.; Rocca, F. Nonlinear subsidence rate estimation using permanent scatterers in differential SAR interferometry. IEEE Trans. Geosci. Remote Sens. 2000, 38, 2202-2212. [CrossRef]

68. Costantini, M.; Falco, S.; Malvarosa, F.; Minati, F.; Trillo, F.; Vecchioli, F. Persistent scatterer pair interferometry: Approach and application to COSMO-SkyMed SAR data. IEEE J. Sel. Top. Appl. Earth Obs. Remote Sens. 2014, 7, 2869-2879. [CrossRef]

69. Costantini, M.; Falco, S.; Malvarosa, F.; Minati, F. A new method for identification and analysis of persistent scatterers in series of SAR images. In Proceedings of the IGARSS 2008-2018 IEEE International Geoscience and Remote Sensing Symposium, Valencia, Spain, 22-27 July 2008; pp. II-449.

70. Ferretti, A.; Fumagalli, A.; Novali, F.; Prati, C.; Rocca, F.; Rucci, A. A new algorithm for processing interferometric data-stacks: SqueeSAR. Ieee Trans. Geosci. Remote Sens. 2011, 49, 3460-3470. [CrossRef]

71. Notti, D.; Herrera, G.; Bianchini, S.; Meisina, C.; García-Davalillo, J.C.; Zucca, F. A methodology for improving landslide PSI data analysis. Int. J. Remote Sens. 2014, 35, 2186-2214. [CrossRef]

72. Geoportal of the Tuscany Region. Available online: http://www.regione.toscana.it/-/geoscopio (accessed on 15 May 2019).

73. Del Soldato, M.; Bianchini, S.; Calcaterra, D.; De Vita, P.; Martire, D.D.; Tomás, R.; Casagli, N. A new approach for landslide-induced damage assessment. Geomat. Nat. Hazards Risk 2017, 8, 1524-1537. [CrossRef]

74. Cooper, A.H. The classification, recording, databasing and use of information about building damage caused by subsidence and landslides. Q. J. Eng. Geol. Hydrogeol. 2008, 41, 409-424. [CrossRef]

75. Burland, J.B.; Wroth, C.P. Settlement of Buildings and Associated Damage; Pentech Press: Cambridge, UK, 1974; pp. 611-654.

76. Baggio, C.; Bernardini, A.; Colozza, R.; Corazza, L. Manuale per la compilazione della scheda di 1 livello di rilevamento danno, pronto intervento e agibilità per edifici ordinari nell'emergenza post-sismica. Ed. Ital. Nel Mondo Srl-Roma 2009.

77. Grünthal, G. (Ed.) European Macroseismic Scale 1998 (EMS-98); European Seismological Commission, sub commission on Engineering Seismology, Working Group Macroseismic Scales: Luxembourg, 1998.

78. Nazri, F.M. Fragility Curves. In Seismic Fragility Assessment for Buildings Due to Earthquake Excitation; Springer: Singapore, 2018; pp. 3-30.

79. Muntasir Billah, A.; Shahria Alam, M. Seismic fragility assessment of highway bridges: A state-of-the-art review. Struct. Infrastruct. Eng. 2015, 11, 804-832. [CrossRef]

80. Hancilar, U.; Çaktı, E.; Erdik, M.; Franco, G.E.; Deodatis, G. Earthquake vulnerability of school buildings: Probabilistic structural fragility analyses. Soil Dyn. Earthq. Eng. 2014, 67, 169-178. [CrossRef]

81. Bartier, P.M.; Keller, C.P. Multivariate interpolation to incorporate thematic surface data using inverse distance weighting (IDW). Comput. Geosci. 1996, 22, 795-799. [CrossRef]

82. Shepard, D. A two-dimensional interpolation function for irregularly-spaced data. In Proceedings of the 1968 23rd ACM National Conference, Las Vegas, NV, USA, 27-29 August 1968; pp. 517-524.

83. Ciampalini, A.; Raspini, F.; Bianchini, S.; Lagomarsino, D.; Moretti, S. A Landslide Susceptibility Map of the Messina Province (Sicily, Italy). In Landslides and Engineered Slopes. Experience, Theory and Practice; CRC Press: Boca Raton, FL, USA, 2016.

84. Bardi, F.; Frodella, W.; Ciampalini, A.; Bianchini, S.; Del Ventisette, C.; Gigli, G.; Fanti, R.; Moretti, S.; Basile, G.; Casagli, N. Integration between ground-based and satellite SAR data in landslide mapping: The San Fratello case study. Geomorphology 2014, 223, 45-60. [CrossRef]

85. Zhang, Y.; Meng, X.; Jordan, C.; Novellino, A.; Dijkstra, T.; Chen, G. Investigating slow-moving landslides in the Zhouqu region of China using InSAR time series. Landslides 2018, 15, 1299-1315. [CrossRef]

86. Béjar-Pizarro, M.; Notti, D.; Mateos, R.M.; Ezquerro, P.; Centolanza, G.; Herrera, G.; Bru, G.; Sanabria, M.; Solari, L.; Duro, J. Mapping vulnerable urban areas affected by slow-moving landslides using Sentinel-1 InSAR data. Remote Sens. 2017, 9, 876. [CrossRef]

87. Raspini, F.; Bianchini, S.; Ciampalini, A.; Del Soldato, M.; Solari, L.; Novali, F.; Del Conte, S.; Rucci, A.; Ferretti, A.; Casagli, N. Continuous, semi-automatic monitoring of ground deformation using Sentinel-1 satellites. Sci. Rep. 2018, 8, 1-11. [CrossRef]

(C) 2019 by the authors. Licensee MDPI, Basel, Switzerland. This article is an open access article distributed under the terms and conditions of the Creative Commons Attribution (CC BY) license (http://creativecommons.org/licenses/by/4.0/). 